\title{
Sequence Control System of 1 MW, 352.2 Mhz CW Klystron Amplifier
}

\author{
A. Tripathi", R. Upadhyay, J. N. Rao, M. K. Badapanda, P. R. Hannurkar \\ Raja Ramanna Centre For Advanced Technology, 452013, Indore \\ *Corresponding Author: atripathi@rrcat.gov.in
}

Copyright (C) 2013 Horizon Research Publishing All rights reserved.

\begin{abstract}
A 1 MW, 352.2 MHz, RF test set up based on Thales make TH 2089 klystron amplifier, having both CW and pulsed capability is being developed at Raja Ramanna Centre for Advanced Technology (RRCAT), Indore for characterization and qualification of RF components, cavities and related subsystems. Provision to vary RF power from $50 \mathrm{~kW}$ to $1 \mathrm{MW}$ with adequate flexibility for testing wide range of RF components has been incorporated in this test set up. A high power radio frequency (RF) system is always equipped with an interlock and protection circuit for its reliable and safe operation. In an RF system, RF input, all the DC bias power supplies and water cooling parameters like flow and temperature need to be switched ON/OFF in a certain predefined timing sequence to prevent damage to the high power RF device (in this case klystron) and its system. So sequence control system is basically for protecting the klystron amplifier. The sequence control system of 1-MW CW klystron has been developed in order to drive the 1-MW, 352.2 MHz klystron amplifier (TH 2089). The system is able to control the operation of several power supplies and many environment conditions. The hardware of sequence control and the interlock system are based on the NI cRIO 9081(Integrated 1.06GHz Dual Core Controller). Proposed application software is built on LabVIEW 2011 platform and designed to work on Microsoft window environment. The basic function of the software is to check and indicate all the interlocks \& $\log$ the data before providing power to klystron. The data in this system is acquired with real time visualization. The software will acquire system parameters like status of various mains and power supplies, RF status, various channel status and selection, interlocking system and other incoming status signal as per predefined test sequence. It process acquired data and control the system to achieve user define goals. Additionally, a protection circuit senses the fault conditions such as overvoltage, over-current, high water/air temperature, low water flow, arcing etc. and generates trips which in turn switch off the supplies in a controlled sequence. Communication between PC and real-time controller is established through standard Ethernet. Provision for offline fault analysis based on settable pre and post trigger mechanism has also been incorporated.
\end{abstract}

Keywords klystron amplifier

\section{Introduction}

The sequence control system of $1 \mathrm{MW}, 352.2 \mathrm{MHz}$ klystron is based on NI cRIO 9081(Integrated 1.06GHz Dual Core Controller). Many different schemes are adopted worldwide for sequence control of RF amplifiers such as PLC based control system. But since data logging is difficult in PLC based system so NI cRIO 9081 is chosen for our application. The developed sequence control system will be used to energise a $1 \mathrm{MW} \mathrm{CW}$ klystron amplifier and the output of this klystron amplifier will be used in characterization and qualification of RF components, cavities and related subsystems [1]. This system overview is shown in Fig.1. The control system is designed mainly for controlling the sequence of operation of various power supplies such as $-100 \mathrm{kV}$ high voltage power supply, filament power supply, modulating anode power supply, electromagnet power supply and ion pump power supply. The complete system, controlling various power supplies is shown in Fig. 2. It also controls and monitors cooling water temperature, pressure and flow, oil temperature and cooling air flow. In the end it applies RF signal to the klystron amplifier.

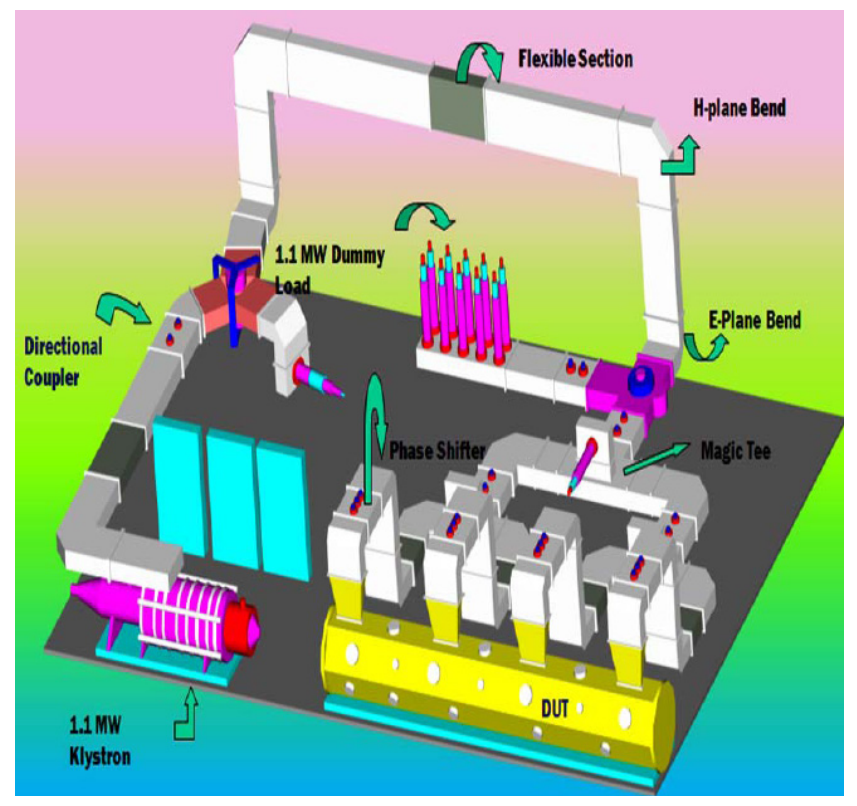

Figure 1. 1 MW RF system 


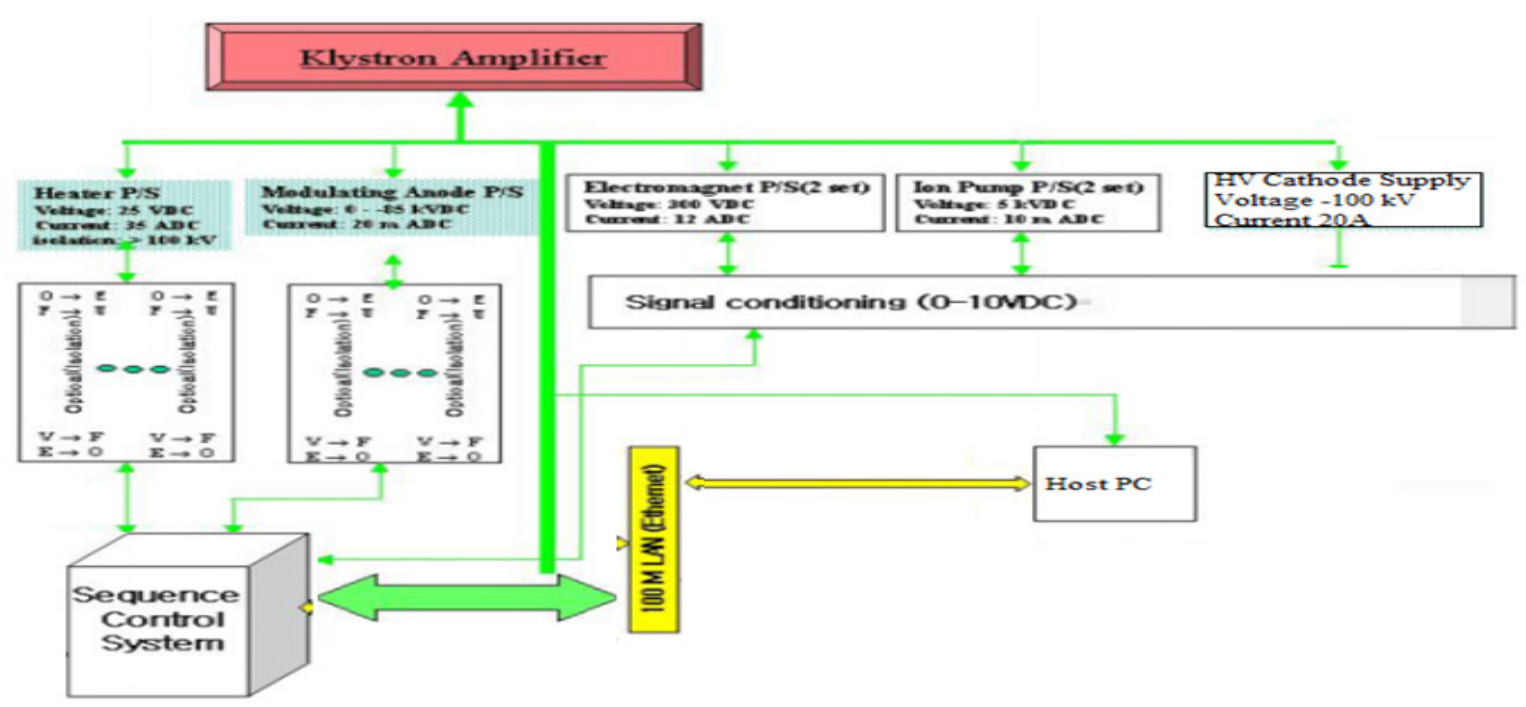

Figure 2. Klystron amplifier and its power supplies along with sequence control system

\section{System Configuration \& Hardware}

The proposed system is having following major hardware part with supported accessories:

- NI cRIO - 9081 (Integrated 1.06GHz Dual Core Controller and LX 75 FPGA)

- NI 9148 (Ethernet RIO Expansion Chassis )

- NI 9208 (16 - Channel Current Input Module)

- NI 9205 (32 - ch $\pm 200 \mathrm{mV}$ to $\pm 10 \mathrm{~V}, 16$ - Bit, $250 \mathrm{kS} / \mathrm{s}$ Analog Input Module)

- NI 9264 (16 Channel Analog Output Module)

- NI 9425 (32 ch, 24V, $7 \mu \mathrm{S}$, Sinking Digital Input Module)

- NI 9477 (32 ch, $8 \mu \mathrm{S}, 5$ to 60V, Sinking Digital Output Module)

- NI 9223 (16 bit, +/ - 10V, Fast Analog Voltage Input Module)

- NI 9401 (8 ch, 5V/TTL, High speed Bidirectional Digital I/O Module)

Out of these NI cRIO-9081 is the main controller which is used for processing $\mathrm{I} / \mathrm{O}$ signals and others are $\mathrm{I} / \mathrm{O}$ modules. The Operating system of the cRIO controller will be NI Lab View Real Time system. The control signal consists of 80 digital input signals, 80 digital output signals, 16 anolog input signals, 16 anolog output signals and 16 analog input (current) signals.

\section{Connection Description of Hardware}

The real time data acquisition by hardware cRIO \& FPGA $\mathrm{I} / \mathrm{O}$ are system's access point to field instruments (I/O modules). It acquires and continuously monitors the status and control signals for various power supplies, air and water flow switches, temperature sensors, smoke detectors and Controls field instruments. Connection of hardware with host PC is shown in Fig. 3. The real time data acquisition hardware in turn communicates with host work station on Ethernet. Workstation carries host application software which provides graphical user interface to user.

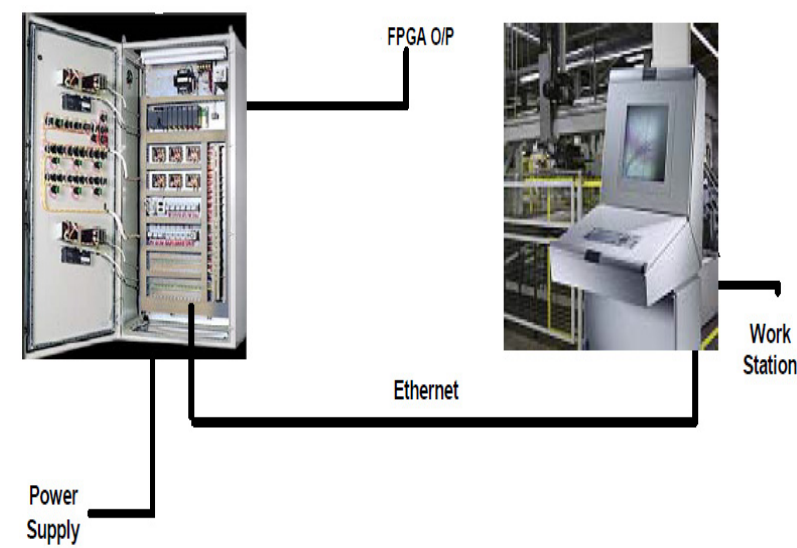

Figure 3. Connection of Hardware with Host PC

\section{Software Architecture}

The software is divided into three major parts 1) Host application, 2) Real time data acquisition and control module and 3) FPGA based program that is used to acquire data from field instruments \& sensors and generates control signals for power supplies, air and water flow switches, temperature sensors and smoke detectors. FPGA based program works in between host application and data acquisition hardware and do not have any user interface. The host application takes cares of graphical user interface. The real time data acquisition and FPGA based program acquires and controls I/O channels deterministically. The determinism provided by real time data acquisition and control module enable us to sample I/O channels at equal time slices providing better controls.

\section{Sequence Control System of 1-MW CW Klystron}

Sequence control of $1 \mathrm{MW}$ klystron amplifier starts by checking that heater voltage is $0 \mathrm{~V}$ and voltage of ion pump power supply1, 2 is $4.5-5.5 \mathrm{kV}$ and current of ion pump power supply1, 2 is bellow $10 \mathrm{uA}$. Now normal condition of 
Klystron collector, Klystron Body, Klystron Cavity output, Circulator, Circulator load, water flow, Dummy load inlet temperature and Klystron window air cooling is checked. If everything is normal, it becomes black heater ready status.

Black Heater Mode: In Black Heater Mode, if we set heater current to $25 \mathrm{~A}$ and it is same with reading value, begin to count with 15 -minute time delay. Within this 15 minute delay, filament current is increased from $0 \mathrm{~A}$ to $25 \mathrm{~A}$ slowly. At the same time electromagnet 1,2 power supplies are turned ON. If electromagnet power supply current is between $9 \mathrm{~A}$ and $12 \mathrm{~A}$, electromagnet power is OK status. Now after 15-minute delay, it becomes black heater normal status and standby ready status.

Standby Mode In this mode if we set heater current to $25 \mathrm{~A}$ and it is same with reading value, if heater voltage is between $19 \mathrm{~V}$ and $20 \mathrm{~V}$, full heater voltage is OK status. In this case, modulating anode power supply is turned ON. If everything is normal, it becomes standby OK and ready for HV status.

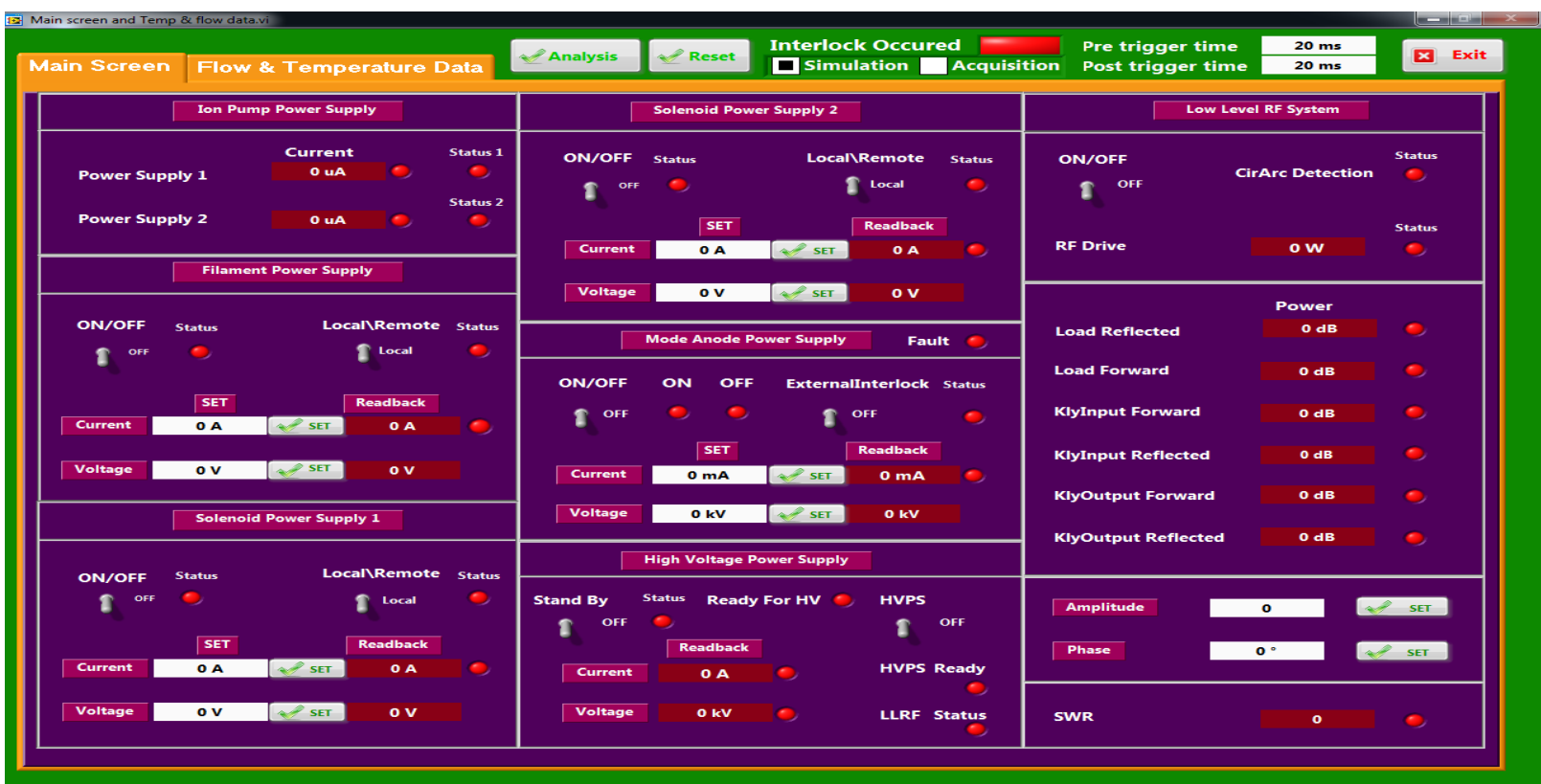

Figure 4. Main Screen

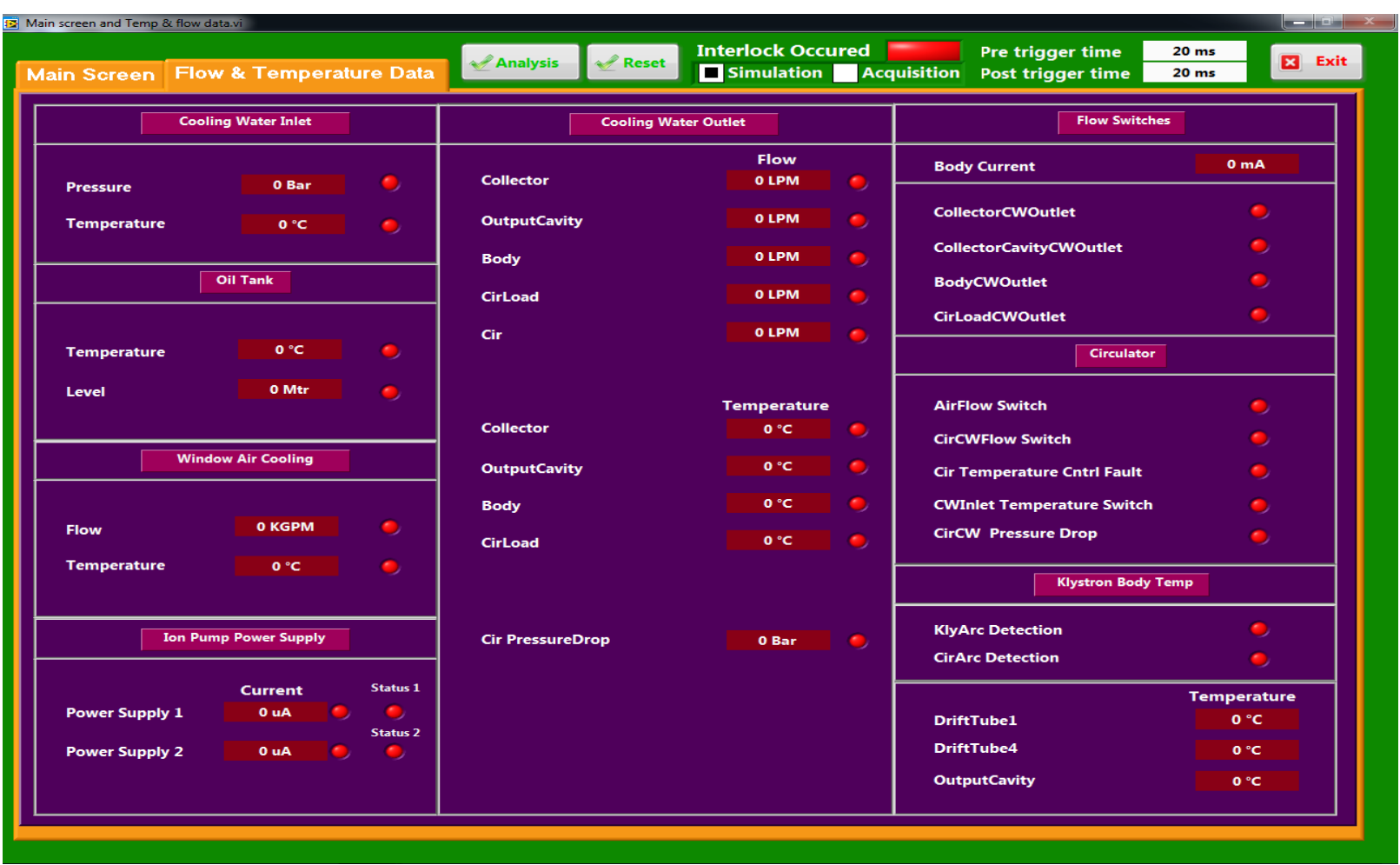

Figure 5. Flow and temperature Data 
High Voltage Mode: In this mode operating beam voltage is set and applied to the klystron amplifier. If beam voltage is same with the setting values, it is HVPS ready status. If klystron window arc, reflect RF power, circulator arc are normal, LLRF switch is turned ON now. Now ion pump 1,2 voltage/current, klystron inlet water temperature, Klystron collector temperature, Klystron body/cavity temperature, dummy load inlet/outlet temperature, Klystron collector water flow, dummy load water flow, forward/reflected RF power can be monitored on the front panel of the host PC [2]. Fig. 4 presents the developed main screen where data from various power supplies are shown. Fig. 5 shows the flow and temperature data.

\subsection{Protection Sequence}

In parallel to interlocking, the protection circuit keeps a check on any fault such as low water flow, high water temperature, over voltage and over current, under voltage in all the bias supplies, arc detection from klystron window, circulator, RF windows and vacuum deterioration etc. The protection circuit senses these trips and switches off the required bias supplies in a predefined sequence in response to the particular trip generated.

\section{Conclusions}

The sequence control system is developed for the Thales make TH 2089, 1 MW, 352.2 MHz klystron amplifier. It controls the sequence of application of various bias power supplies to the klystron, controls and monitors the various temperatures, water flows and protects klystron in case of any fault. This system will be integrated with the $1 \mathrm{MW}$ klystron amplifier (TH 2089) soon.

\section{REFERENCES}

[1] Badapanda, M.K. ; Tripathi, A. ; Upadhyay, R. and Hannurkar, P.R.; Development of $352.2 \mathrm{MHz}$ high power RF test setup, Vacuum Electronics Conference (IVEC), 2011 IEEE International , p $485-486$

[2] B.R. Park, M.H. Chun, J.S. Yang, S.C. Kim, M.H. Jeong, I.H. Yu, Y.J. Han and J.H. Choi, SEQUENCE CONTROL SYSTEM OF 1-MW CW KLYSTRON FOR THE PEFP, Proceedings of 2005 Particle Accelerator Conference, noxville, Tennessee, p 1401-1403 